\title{
The APOB loss-of-function mutation of Holstein dairy cattle does not cause a deficiency of cholesterol but decreases the capacity for cholesterol transport in circulation
}

\author{
J. J. Gross, ${ }^{1}$ A.-C. Schwinn, ${ }^{1}$ F. Schmitz-Hsu, ${ }^{2}$ A. Barenco, ${ }^{3}$ T. F.-O. Neuenschwander, ${ }^{4}$ C. Drögemüller, ${ }^{5}$ \\ and R. M. Bruckmaier ${ }^{1 *}$ \\ ${ }^{1}$ Veterinary Physiology, Vetsuisse Faculty, University of Bern, 3012 Bern, Switzerland \\ ${ }^{2}$ Swissgenetics, 3052 Zollikofen, Switzerland \\ ${ }^{3}$ Swissherdbook, 3052 Zollikofen, Switzerland \\ ${ }^{4}$ Holstein Switzerland, 1725 Posieux, Switzerland \\ ${ }^{5}$ Institute of Genetics, Vetsuisse Faculty, University of Bern, 3012 Bern, Switzerland
}

\section{ABSTRACT}

The loss-of-function mutation of the apolipoprotein $(\mathrm{APO}) \mathrm{B}$ gene $(A P O B)$ in Holstein cattle accounts for increased losses in calves that are homozygous for this mutation. Heterozygous carriers of the $A P O B$ mutation are clinically healthy but show decreased concentrations of plasma cholesterol and lipoproteins. So far, the metabolic effects of the mutation have only been investigated in heterozygous calves, bulls, and nonlactating females. In high-yielding dairy cows, a marked decrease in cholesterol concentration in plasma during early lactation is part of the usual metabolic changes. Given the essential role of cholesterol in fatty acid and lipid metabolism, a specific effect of the $A P O B \mathrm{mu}-$ tation on metabolism and performance in dairy cows is expected. Therefore, the aim of the present study was to investigate the effects of different $A P O B$ genotypes on metabolic parameters, hepatic metabolism, and lactation and reproductive performance. Twenty pairs of full siblings with similar age, performance, and calving were investigated. Both animals of each pair were kept on the same farm and consisted of a heterozygous carrier (CDC) and a noncarrier (CDF) of the $A P O B$ mutation associated with cholesterol deficiency. Blood samples were taken in early $(25.5 \pm 4.7$ $\mathrm{d}$ in milk) and mid lactation $(158.2 \pm 11.1 \mathrm{~d}$ in milk; mean $\pm \mathrm{SD}$ ), and analyzed for nonesterified fatty acids, $\beta$-hydroxybutyrate, glucose, insulin-like growth factor-1, aspartate aminotransferase and gamma-glutamyltransferase activity, total cholesterol, free cholesterol, triacylglycerols, high density lipoprotein-cholesterol, and phospholipids. The evaluation of milk production,

Received April 24, 2019.

Accepted July 15, 2019.

*Corresponding author: rupert.bruckmaier@vetsuisse.unibe.ch milk gross composition, and lactation persistency was based on official Dairy Herd Improvement Association recordings. Cholesterol and lipoprotein concentrations were lower in CDC cows than in CDF cows in early and mid lactation. Metabolic parameters, triacylglycerol concentration in plasma, and lactation and reproductive performance did not differ between CDC cows and CDF cows. The low cholesterol concentrations associated with the $A P O B$ mutation in heterozygous carriers are not because of a primary deficiency of cholesterol at a cellular level, as the term "cholesterol deficiency" suggests, but rather a consequence of reduced capacity for its transport in circulation. Overall, the data of the present study suggest that, despite the presence of the $A P O B$ mutation, cholesterol is not limiting for animals' metabolic adaptation and performance in heterozygous Holstein cows.

Key words: cholesterol deficiency, cholesterol, $A P O B$ mutation, lipoprotein, dairy cow

\section{INTRODUCTION}

Metabolic adaptations in lipid metabolism of dairy cows after parturition involve mobilization of fatty acids from fat depots, their transport, and their utilization in target organs. The energy deficiency resulting from low feed intake at concomitantly high demands for milk synthesis needs to be covered by a considerable breakdown of adipose tissue, resulting in elevated concentrations of nonesterified fatty acids (NEFA) in circulation (Grummer, 1993; Gross et al., 2011). The liver is the primary organ where released NEFA are oxidized for energetic purposes. Concomitantly, the hepatic export of triacylglycerols (TAG) is ensured by very low density lipoproteins (VLDL) that consist of apolipoprotein (APO) $\mathrm{B}_{100}$, cholesterol, phospholipids, and TAG (Kessler et al., 2014). However, excessive 
delivery of fatty acids may overstrain hepatic oxidation and export capacities. As a result, NEFA are reesterified to TAG (and stored in the liver, resulting in hepatic steatosis) and converted to ketone bodies such as BHB, contributing to the development of fatty liver and ketonemia, which negatively affect animal health and performance (Bobe et al., 2004; Gross et al., 2013).

Besides its role in hepatic TAG export, cholesterol is an essential part of biological membranes and a substrate for bile acid and steroid hormone synthesis. Recently, a loss-of-function mutation of the $A P O B$ gene was discovered in Holstein cattle (OMIA 001965-9913, https://omia.org/OMIA001965/9913/; Kipp et al., 2016; Menzi et al., 2016). Homozygous carriers of this mutation died soon after birth and showed extremely low concentrations of plasma cholesterol that led to it being named "cholesterol deficiency (CD)" before understanding the biological effects of the mutation (Duff et al., 2016; Kipp et al., 2016; Mock et al., 2016; Schütz et al., 2016). Heterozygous calves, bulls, and nonlactating females are clinically healthy but express distinctly lesser cholesterol and lipoprotein concentrations compared with noncarriers (Gross et al., 2016; Saleem et al., 2016). Recently, a series of $A P O B$ heterozygote calves were reported that show the clinical CD phenotype (Häfliger et al., 2019). Therefore, it could be assumed that the CD disorder most likely represents an incomplete dominant inherited metabolic disease with incomplete penetrance in heterozygotes. Heterozygous carriers of the loss-of-function mutation in $A P O B$ account for approximately $9 \%$ in the Holstein dairy cow population in Germany (Kipp et al., 2016; Saleem et al., 2016), whereas Cole et al. (2018) and Schütz et al. (2016) estimated up to 5\% carriers in the European and North American Holstein populations, respectively. Depending on the use of carrier sires, the frequency can be assumed to be much higher in individual farms and regions. Although risk-matings bearing a high risk for homozygous affected offspring have been avoided since the discovery and causal description of the $A P O B$-associated haplotype, Holstein cattle carrying the $A P O B$ mutation have not been eradicated.

Dairy cows experience a marked decrease in cholesterol concentration in plasma during early lactation (Kessler et al., 2014; Gross et al., 2015). Given the essential role of cholesterol in fatty acid and lipid metabolism, the effect of the $A P O B$ mutation on intermediary metabolism and milk yield of Holstein dairy cows are unknown. Therefore, the aim of the present study was to investigate the effects of different $A P O B$ genotypes on metabolic parameters, hepatic metabolism, and lactational and reproductive performance. We hypothesized that in heterozygous carriers of the $A P O B$ mutation, circulating cholesterol concentrations are lower than those in noncarriers. Two distinct lactational stages were evaluated to determine whether effects of the CD-associated $A P O B$ mutation are persistent or more evident in early lactation.

\section{MATERIALS AND METHODS}

The experimental procedures followed the Swiss Law on animal protection and were approved by the responsible cantonal committees of animal protection and animal welfare issues.

\section{Animal Selection and Genotyping}

Pedigrees of Holstein dairy cows in Switzerland were evaluated to identify CD animals with a high likelihood of carrying the genetic mutation in the $A P O B$ gene. To determine individual $A P O B$ genotypes, we used a PCR-based direct gene test, as previously described by Menzi et al. (2016). Across the cantons north of the Swiss Alps, 20 pairs of matched siblings of Holstein dairy cows each with a heterozygous carrier of the mutation (CDC) and a noncarrier (CDF) were selected from different farms. Each pair of cows was kept under identical environmental and feeding conditions on the same farm. Matching criteria were same parity number and a similar age, performance level, and expected date of calving of the CDC and CDF siblings. Lactation numbers of cows ranged between 1 and $7(2.5 \pm 1.5$, mean $\pm \mathrm{SD}$ ). Pairs were full siblings (6), twins (10), or originated from embryo transfer (4).

\section{Blood Sampling and Analysis}

Based on previous data showing the nadir and development of cholesterol concentrations in early lactation (Kessler et al., 2014; Gross et al., 2015), we selected 2 occasions during lactation for blood sampling when cholesterol concentrations in plasma were expected to differ distinctly as a result of lactational stage. The first blood sampling was performed in early lactation $(25.5 \pm 4.7$ DIM; mean \pm SD), range: 11 to 40 DIM). With one exception, blood in pairs during early lactation was sampled within $6 \mathrm{~d}$. The second blood sample was taken in mid lactation (158.2 \pm 11.1 DIM, range: 141 to 186 DIM). Before the second blood sampling, 4 of the 40 cows were culled. Consequently, sampling of the respective paired sibling was cancelled. Blood was collected through the coccygeal vein into evacuated tubes containing EDTA (Vacuette, Greiner Bio-One GmbH, Kremsmünster, Austria), immediately put on wet ice, and centrifuged $\left(3,000 \times g\right.$ for 20 min at $\left.4^{\circ} \mathrm{C}\right)$; the harvested plasma was stored at $-20^{\circ} \mathrm{C}$ in $1.5-\mathrm{mL}$ snap-vial tubes until analysis. 
Concentrations of NEFA and BHB in plasma were measured with enzymatic kits from Randox Laboratories Ltd. (Schwyz, Switzerland; kit no. FA 115 for NEFA, and kit no. RB 1007 for BHB). Insulin-like growth factor-1 in plasma was measured by RIA as described by Vicari et al. (2008). Concentrations of glucose, total cholesterol (TC), and triacylglycerols (TAG), and the activities of aspartate aminotransferase (AST, EC 2.6.1.1) and gamma-glutamyltransferase (GGT, EC 2.3.2.2) in plasma were measured with kits from bioMérieux (Marcy l'Etoile, France; kit nos. 61270, 61219, 61236, 63212, and 63712, respectively). Phospholipid (PL) and free cholesterol (FC) concentrations in plasma were measured using enzymatic kits from Wako Pure Chemical Industries Ltd. (Osaka, Japan; kit no. 296-63801 for PL, and no. 435-35801 for FC). The concentration of high density lipoprotein-cholesterol (HDL-C) in plasma was measured by using an immunoinhibition method (Wako, kit no. 412-72395). Concentrations of cholesteryl esters (CE), and the sum of low and very low density lipoprotein-cholesterol (LDL-C and VLDL-C) were calculated using the following equations:

$$
\begin{gathered}
\text { CE }=\text { TC }- \text { FC, and } \\
\text { LDL-C }+ \text { VLDL-C }=\text { TC }- \text { HDL-C. }
\end{gathered}
$$

We also calculated the ratios of CE:TC, FC:CE, FC:TC, and PL:TC.

\section{Performance and Animal Health Data}

Data on lactation performance based on the official DHIA samplings every 30 to $37 \mathrm{~d}$ was provided by the breeding associations. Milk data included milk yield and the concentrations of milk fat, protein, lactose, and milk urea. Data of the first 5 DHIA samplings of the current lactation period are presented where blood sampling was performed. Milk was sampled for the first DHIA control at $25 \pm 12$ DIM (range 5-50 DIM), for sampling \#2 at $61 \pm 15$ DIM (range 37-92 DIM), for sampling \#3 at $95 \pm 16$ DIM (range $70-130$ DIM), for sampling \#4 at $129 \pm 17$ DIM (range 106-166 DIM), and for sampling \#5 at $163 \pm 18$ DIM (range 140-206 DIM). The milk production data recorded at the DHIA control milkings were used to calculate the cumulative $100-d, 200-d$, and 305-d milk production. Four out of the 20 pairs had to be excluded because single animals of the pairs were culled for different reasons before 305 DIM (mastitis: 1 CDC cow in wk 4 postpartum, 1 CDC cow in wk 14 postpartum; fertility issues: $1 \mathrm{CDF}$ cow in wk 28 postpartum; accident: 1 CDF cow in wk 18 post- partum). Culling of animals seemed not to be related to the CD genotype. Therefore, only performance and fertility data of the 16 remaining pairs are presented.

The persistency of the lactation curve was calculated as ratio of milk production in the second (101 to $200 \mathrm{DIM}$ ) to the first trimester (0 to $100 \mathrm{DIM}$ ), and the third (201 to 305 DIM) to the first trimester of lactation, respectively. Fertility data available were restricted to the interval between calving and successful insemination, which might indicate the reproductive performance of animals.

\section{Statistical Analysis}

Data are presented as mean values \pm standard errors of the mean (SEM; except where declared as standard deviations, SD). All statistical analyses were carried out using SAS software (version 9.4, SAS Institute Inc., Cary, NC). A mixed model with genotype and time of sampling as fixed effects was used to assess differences between genotypes and sampling events. Pairs were considered random. The level of significance was set at $P<0.05$.

\section{RESULTS}

\section{Performance and Fertility}

Milk production (Figure 1A) and milk composition [i.e., contents of milk fat (Figure 1B), protein (Figure 1C), lactose (Figure 1D), and urea (Figure 1E)] did not differ between cows with different $A P O B$ genotypes. Furthermore, cumulative milk production at 100, 200, and 305 DIM, and average milk fat and protein contents during these intervals did not differ between CDC and CDF cows (Table 1). Lactation persistency of milk production and the interval between parturition until successful conception were similar across cows of both genotypes (Table 1).

\section{Enzyme Activities, Lipoproteins, and Factors in Plasma Related to Energy Metabolism}

In early and mid lactation, concentrations of $\mathrm{TC}$ (Figure 2A), FC (Figure 2B), CE (Figure 2C), PL (Figure 3A), HDL-C (Figure 3C), and LDL-C + VLDL-C (Figure 3D) in plasma were lower in CDC cows than in CDF cows $(P<0.0001$ to $P<0.01)$. In both CDC and CDF cows, the respective lipoprotein-cholesterol concentrations increased from early to mid lactation $(P<0.01)$. The ratios of CE:TC, FC:CE, FC:TC, and PL:TC did not differ between CDC cows and CDF cows in early or mid lactation $(P>0.05$; data not shown). The concentration of TAG in plasma did not 


\section{$\rightarrow$ CDC \\ $\rightarrow-$ CDF}
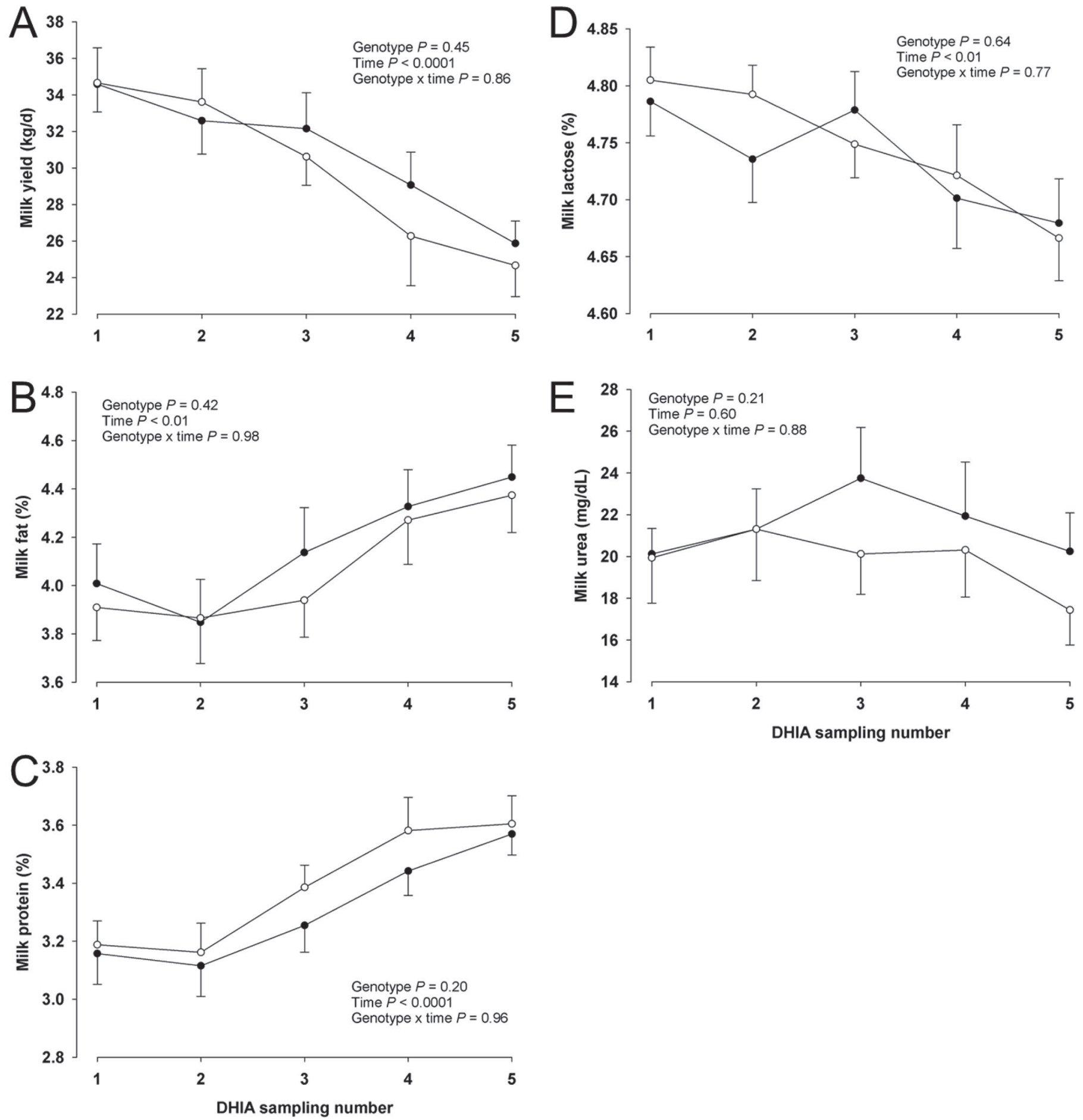

Figure 1. Milk yield (A), contents of milk fat (B), protein (C), lactose (D), and urea (E) in Holstein dairy cows [carrying the loss-of-function mutation of the $A P O B$ gene (CDC) and noncarriers (CDF)] during the first 5 DHIA samplings after parturition. Data are mean values \pm SEM of 16 pairs of CDC and CDF cows. 
Table 1. Cumulative milk production and milk composition at 100, 200, and 305 DIM in Holstein dairy cows carrying the loss-of-function mutation of the $A P O B$ gene $(\mathrm{CDC})$, and noncarriers $(\mathrm{CDF})^{1}$

\begin{tabular}{|c|c|c|c|}
\hline \multirow[b]{2}{*}{ Item } & \multicolumn{2}{|c|}{ Genotype } & \multirow{2}{*}{$\begin{array}{c}P \text {-value } \\
\text { CDC vs. CDF }\end{array}$} \\
\hline & $\mathrm{CDC}$ & $\mathrm{CDF}$ & \\
\hline \multicolumn{4}{|l|}{ Cumulative milk production } \\
\hline \multicolumn{4}{|l|}{ 0-100 DIM } \\
\hline Milk yield $(\mathrm{kg})$ & $3,317 \pm 151$ & $3,351 \pm 176$ & 0.89 \\
\hline Milk fat $(\%)$ & $3.94 \pm 0.13$ & $3.88 \pm 0.12$ & 0.70 \\
\hline Milk protein (\%) & $3.12 \pm 0.08$ & $3.26 \pm 0.07$ & 0.22 \\
\hline \multicolumn{4}{|l|}{ 0-200 DIM } \\
\hline Milk yield $(\mathrm{kg})$ & $6,014 \pm 314$ & $5,934 \pm 333$ & 0.86 \\
\hline Milk fat (\%) & $3.96 \pm 0.14$ & $3.93 \pm 0.12$ & 0.87 \\
\hline Milk protein (\%) & $3.13 \pm 0.09$ & $3.22 \pm 0.08$ & 0.46 \\
\hline \multicolumn{4}{|l|}{ 0-305 DIM } \\
\hline Milk yield $(\mathrm{kg})$ & $8,206 \pm 433$ & $8,230 \pm 433$ & 0.97 \\
\hline Milk fat $(\%)$ & $3.99 \pm 0.27$ & $4.20 \pm 0.14$ & 0.49 \\
\hline Milk protein (\%) & $3.33 \pm 0.07$ & $3.40 \pm 0.08$ & 0.48 \\
\hline \multicolumn{4}{|l|}{ Lactation persistency } \\
\hline Ratio second to first trimester & $0.82 \pm 0.02$ & $0.79 \pm 0.04$ & 0.42 \\
\hline Ratio third to first trimester & $0.66 \pm 0.04$ & $0.70 \pm 0.06$ & 0.57 \\
\hline \multicolumn{4}{|l|}{ Reproductive performance } \\
\hline Days open & $120 \pm 15$ & $117 \pm 18$ & 0.91 \\
\hline
\end{tabular}

${ }^{1}$ Data are mean values \pm SEM of 16 pairs of CDC and CDF cows.

differ between the $2 A P O B$ genotypes at both samplings and was not affected by lactational stage (Figure 3B; $P>0.05)$. Concentrations of glucose, NEFA, BHB, and IGF-1, as well as activities of AST and GGT in plasma, did not differ between CDC cows and CDF cows in early and mid lactation $(P>0.05$; Table 2$)$. Concentrations of plasma glucose, IGF-1, and activity of GGT were lower in CDC and CDF cows in early lactation than in mid lactation, whereas concentrations of NEFA and BHB were higher in early lactation $(P<$ 0.05 ; Table 2 ). The activity of AST was not affected by lactational stage (Table 2).

\section{DISCUSSION}

\section{Effects of APOB Mutation on Animal Performance, Energy Metabolism, Cholesterol, and Lipoproteins in Heterozygous Mutation Carriers}

The effect of the $A P O B$ loss-of-function mutation associated with $\mathrm{CD}$ on animal health and performance has not previously been investigated in lactating dairy cows that are heterozygous carriers of the mutation. It could be assumed that the individual $A P O B$ genotype does not adversely affect - or could even improve - milk production and metabolic status, because mutation carriers are still in the production cycle, although dairy cows are facing a high culling rate because of health disorders and insufficient lactational and reproductive performance. In this study, the examined Holstein dairy cows, regardless of $A P O B$ genotype, showed a similar milk yield and composition throughout the period of sampling from early to mid lactation. Furthermore, persistency of lactation did not differ between genotypes.

Similar to results in calves, bulls, and nonlactating females (Gross et al., 2016; Mock et al., 2016; Saleem et al., 2016), we confirmed a lower concentration of cholesterol and cholesterol in lipoproteins in plasma of CDC cows in early and mid lactation. Low concentrations of total cholesterol and plasma cholesterol partitioned in different lipoproteins are characteristic for cows in early lactation (Schlegel et al., 2012; Kessler et al., 2014; Gross et al., 2015), although the respective concentrations in CDC cows were further decreased in early lactation compared with that in CDF cows. During the intense lipomobilization after parturition, the ability of the liver to handle NEFA may be overloaded, and cows are exposed to an elevated risk of developing fatty liver (Bobe et al., 2004; Gross et al., 2013) or metabolic disorders such as ketosis (McArt et al., 2012; Suthar et al., 2013; Brunner et al., 2019), or have reduced reproductive performance (Walsh et al., 2007; Raboisson et al., 2014). Low cholesterol concentrations in circulation and in the liver are assumed to limit hepatic TAG export via VLDL (Kulinski et al., 2002; Kessler et al., 2014). We can speculate that the lower cholesterol concentrations in CDC cows could be limiting for hepatic functions such as TAG export, particularly during early lactation and steroid hormone synthesis. The estimation of VLDL-C by circulating TAG in plasma (Friedewald et al., 1972) is only plausible if APOB as a component for VLDL formation is not limiting. In the present study, plasma TAG did not differ 

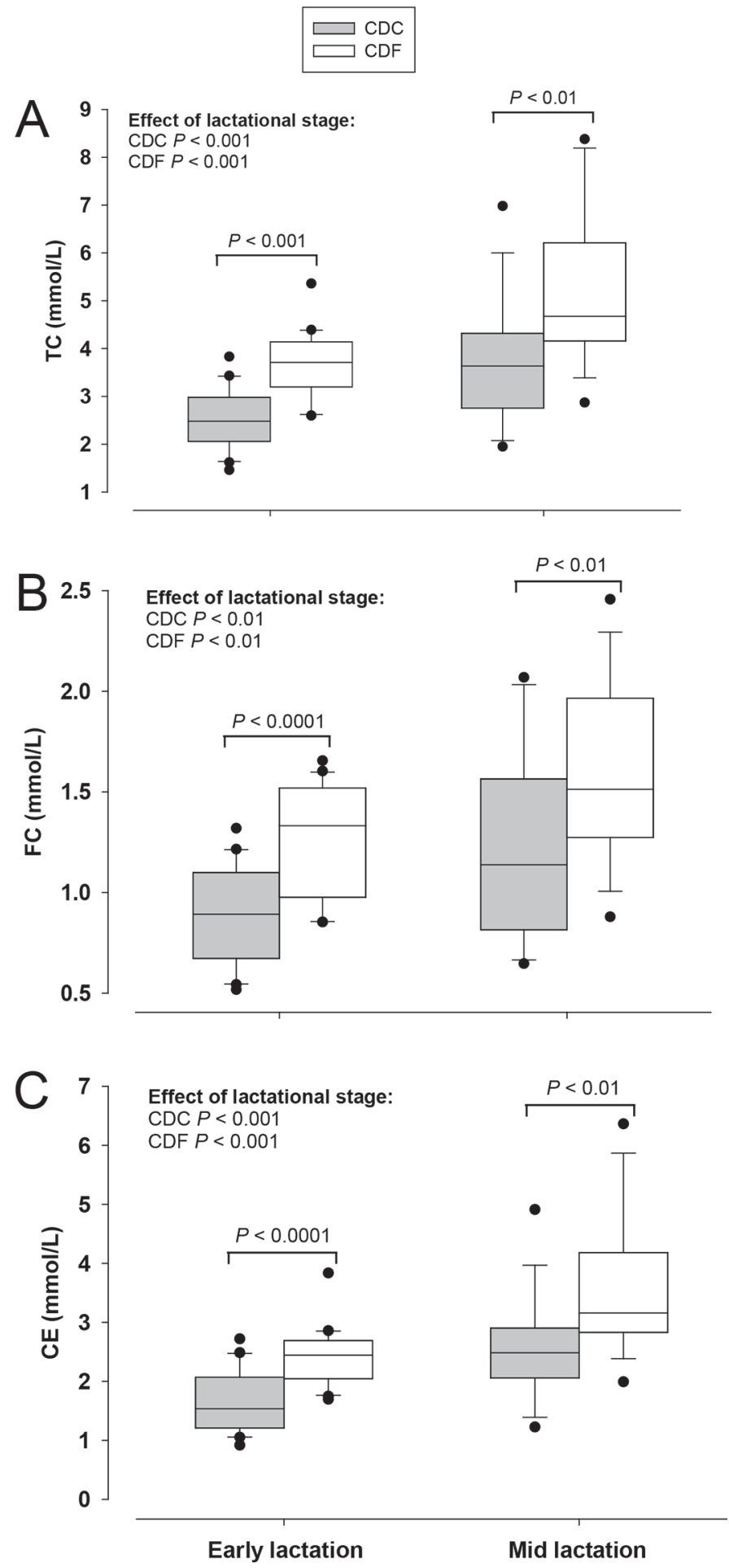

Figure 2. Concentrations of plasma total cholesterol (TC; A), free cholesterol (FC; B), and cholesteryl esters (CE; C) in Holstein dairy cows [carrying the loss-of-function mutation of the $A P O B$ gene (CDC) and noncarriers (CDF)] in early and mid lactation. The box represents the 25 th to 75 th, whiskers the 10th and 90th percentiles, and the solid line in the box the median. Differences between genotypes and effects of lactational stage within genotype were considered significant at $P$ $<0.05$. between $A P O B$ genotypes, which could falsely suggest similar VLDL-C concentrations in CDC cows and CDF cows, whereas all cholesterol and lipoprotein fractions differed between the 2 genotypes. The lack of difference in the ratios of CE:TC, FC:CE, FC:TC, and PL:TC indicate that processes such as esterification of $\mathrm{FC}$ and relative proportions of lipoproteins are not affected by the mutation. We further speculate that the mutation not only affects formation of $\mathrm{APOB}_{100}$ required for circulating LDL, but further decreases circulating HDL as a result of a decreased loading with cholesterol. We expected that CDC cows would have greater concentrations of NEFA and BHB, despite similar milk yield, and potentially a greater extent of fatty liver. However, analysis of plasma metabolites did not confirm our hypothesis of a higher metabolic load in CDC cows than in CDF cows. Likewise, concentrations of TAG in plasma were similar in CDC cows and CDF cows of the present study, suggesting that hepatic lipid export was not impaired. However, sampling in early lactation was performed on average between 3 and 4 wk of lactation, when the most prominent metabolic stress is over (Gross et al., 2011). As we did not obtain liver biopsies, we could not directly investigate hepatic TAG content. Instead, we determined the plasma activities of AST and GGT (although their activity is not exclusively restricted to the liver), giving at least an indication of hepatic function status. Activities of AST and GGT are markers indicating clinical or subclinical hepatic diseases such as liver lipidosis (Cebra et al., 1997; Stojević et al., 2005) or ketosis in dairy cows (Steen, 2001). The damage of liver cells and tissue releases AST and GGT into the blood, raising their measurable activities (Kauppinen, 1984; Stojević et al., 2005). According to veterinary treatment records of the farmers, CDC animals did not behave differently compared with CDF cows. Furthermore, the interval between parturition and successful insemination did not differ between $A P O B$ genotypes, suggesting that cholesterol was not limiting for steroid hormone synthesis related to reproductive performance. Nonetheless, a recent study showed that $A P O B$ carrier status has considerable negative effects on pregnancy and conception rates (Cole et al., 2016). Reduced reproductive performance might be caused by a proportion of embryos and fetuses homozygous for the $A P O B$ loss-of-function mutation dying at different stages of pregnancy or immediately before birth.

\section{Does the APOB Mutation Cause a Cholesterol Deficiency?}

Despite markedly reduced circulating concentrations of cholesterol and lipoproteins in CDC cows compared with CDF cows, individual animal health, performance, 

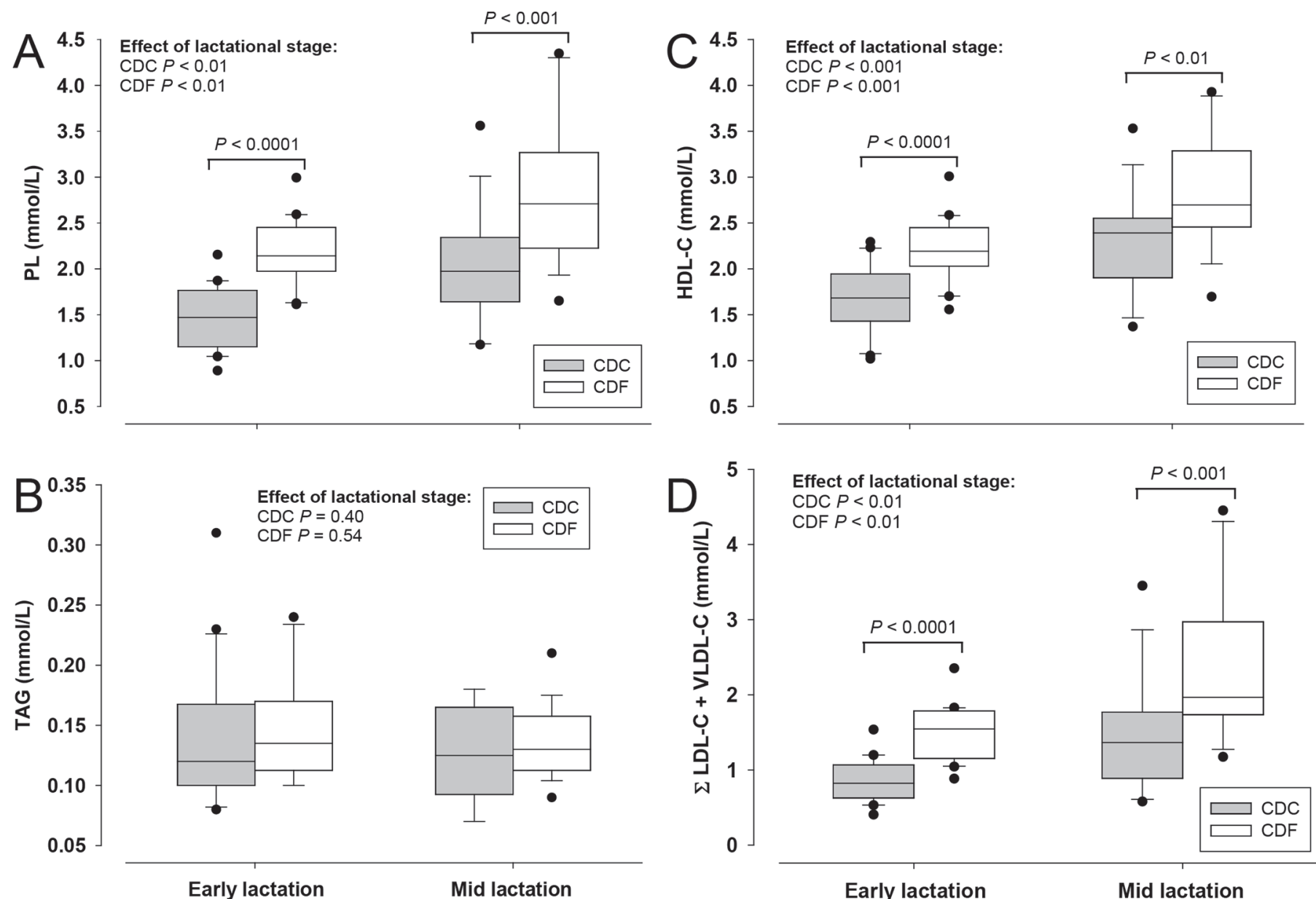

Early lactation

Mid lactation

Figure 3. Concentrations of plasma phospholipids (PL; A), triacylglycerols (TAG; B), high density lipoprotein-cholesterol (HDL-C; C), and the sum of low and very low density lipoprotein-cholesterol (LDL-C + VLDL-C; D) in Holstein dairy cows [carrying the loss-of-function mutation of the $A P O B$ gene $(\mathrm{CDC})$ and noncarriers $(\mathrm{CDF})]$ in early and mid lactation. The box represents the 25th to 75th, whiskers the 10th and 90th percentiles, and the solid line in the box the median. Differences between genotypes and effects of lactational stage within genotype were considered significant at $P<0.05$.

Table 2. Concentrations of glucose, nonesterified fatty acids (NEFA), BHB, IGF-1, and activities of aspartate aminotransferase (AST) and gamma-glutamyltransferase (GGT) in plasma of Holstein dairy cows carrying the loss-of-function mutation of the $A P O B$ gene (CDC) and noncarriers $(\mathrm{CDF})^{1}$

\begin{tabular}{|c|c|c|c|c|c|c|c|c|}
\hline \multirow[b]{2}{*}{ Parameter } & \multicolumn{2}{|c|}{ Early lactation } & \multirow{2}{*}{$\begin{array}{c}P \text {-value: } \\
\text { CDC vs. } \\
\text { CDF }\end{array}$} & \multicolumn{2}{|c|}{ Mid lactation } & \multirow{2}{*}{$\begin{array}{c}P \text {-value: } \\
\text { CDC vs. } \\
\text { CDF }\end{array}$} & \multicolumn{2}{|c|}{$\begin{array}{c}P \text {-value: early } \\
\text { vs. mid lactation }\end{array}$} \\
\hline & $\mathrm{CDC}$ & $\mathrm{CDF}$ & & $\mathrm{CDC}$ & $\mathrm{CDF}$ & & $\mathrm{CDC}$ & $\mathrm{CDF}$ \\
\hline Glucose $(\mathrm{mmol} / \mathrm{L})$ & $\begin{array}{l}3.02 \pm 0.10 \\
\quad(2.02-3.80)\end{array}$ & $\begin{array}{l}3.10 \pm 0.08 \\
\quad(2.38-3.80)\end{array}$ & 0.38 & $\begin{array}{l}3.31 \pm 0.07 \\
\quad(2.84-3.96)\end{array}$ & $\begin{array}{l}3.28 \pm 0.06 \\
\quad(2.84-3.68)\end{array}$ & 0.50 & $<0.001$ & $<0.05$ \\
\hline NEFA $(\mathrm{mmol} / \mathrm{L})$ & $\begin{array}{l}0.36 \pm 0.06 \\
\quad(0.04-1.10)\end{array}$ & $\begin{array}{l}0.28 \pm 0.06 \\
\quad(0.06-1.24)\end{array}$ & 0.28 & $\begin{array}{l}0.05 \pm 0.01 \\
\quad(0.01-0.22)\end{array}$ & $\begin{array}{l}0.06 \pm 0.01 \\
\quad(0.02-0.11)\end{array}$ & 0.84 & $<0.001$ & $<0.01$ \\
\hline IGF-1 (ng/mL) & $\begin{array}{l}71.9 \pm 7.7 \\
\quad(22.4-165.9)\end{array}$ & $\begin{array}{l}75.9 \pm 7.5 \\
\quad(33.3-152.3)\end{array}$ & 0.64 & $\begin{array}{l}101.5 \pm 5.7 \\
\quad(44.8-150.3)\end{array}$ & $\begin{array}{l}96.8 \pm 7.2 \\
\quad(47.0-153.7)\end{array}$ & 0.61 & $<0.0001$ & $<0.01$ \\
\hline AST (U/L) & $\begin{array}{l}76.3 \pm 2.8 \\
\quad(56.0-108.0)\end{array}$ & $\begin{array}{l}75.9 \pm 4.2 \\
\quad(51.0-140.0)\end{array}$ & 0.93 & $\begin{array}{l}83.4 \pm 6.3 \\
\quad(59.0-158.0)\end{array}$ & $\begin{array}{l}78.6 \pm 6.4 \\
\quad(47.0-144.0)\end{array}$ & 0.51 & 0.28 & 0.66 \\
\hline GGT (U/L) & $\begin{array}{l}22.3 \pm 0.9 \\
\quad(14.0-30.0)\end{array}$ & $\begin{array}{l}22.4 \pm 0.9 \\
\quad(16.0-32.0)\end{array}$ & 0.92 & $\begin{array}{l}29.1 \pm 2.1 \\
\quad(18.0-52.0)\end{array}$ & $\begin{array}{l}28.7 \pm 1.9 \\
\quad(16.0-44.0)\end{array}$ & 0.79 & $<0.01$ & $<0.001$ \\
\hline
\end{tabular}

${ }^{1}$ Data are mean values $\pm \mathrm{SEM}$; data in parentheses indicate the range (minimum to maximum) of the respective parameters. 
and metabolic status were not obviously impaired by the $A P O B$ mutation in heterozygous carrier cows. The term "cholesterol deficiency" was initially introduced for the newly discovered disorder in Holstein calves that showed severe growth retardation and chronic diarrhea without evidence of infection during the first weeks or months of life until death. Clinical biochemistry analysis of blood in all of those animals revealed that circulating cholesterol concentrations were close to zero, without knowing the physiological background. In clinically affected $\mathrm{CD} A P O B$ homozygotes, the absence of APOB required for the formation of chylomicrons in the intestine (Bauchart, 1993; Hooper et al., 2015) results in malabsorption of dietary lipids, and animals die as a result of starvation (Duff et al., 2016; Menzi et al., 2016; Mock et al., 2016; Schütz et al., 2016).

However, cholesterol itself is unlikely to be deficient at a functional level within the cellular metabolism because of the $A P O B$ mutation. The lack of APOB, specifically of $\mathrm{APOB}_{100}$, which represents an indispensable component of the lipoproteins VLDL and LDL (Bauchart, 1993; Hooper et al., 2015), consequently manifests in decreased circulating concentrations of VLDL and LDL. Thus, the capability for incorporating cholesterol into lipoproteins is decreased with the consequence of less cholesterol appearing in circulation. A causal effect of the $A P O B$ mutation on cholesterol synthesis is not known. Because of the apparently unaffected animal health and performance in CDC cows compared with CDF cows, a cholesterol deficit is rather unlikely. Furthermore, cholesterol is an integral component of all cellular membranes and is essential to maintain their functionality. Even in $A P O B$ homozygous Holstein calves clinically affected by CD, sufficient cholesterol can be assumed to be present for the formation of a viable organism. The high mortality in CD-affected $A P O B$ homozygotes can be explained by the lack of ability to absorb and transport dietary lipid components that are a major energy source during the milk-feeding period in calves. Despite significantly lowered concentrations of cholesterol and lipoproteins in $A P O B$ heterozygotes, we detected neither limitations nor advantages for intermediary metabolism, health, lactational and reproductive performance, although recent evidence has shown that some $A P O B$ heterozygotes might show the clinical CD phenotype (Häfliger et al., 2019). Because of the rather late sampling in early lactation, however, the effects of low circulating cholesterol concentrations on short-term metabolic adaptation to fluctuations in energy balance might not have been detected in the present study. Further implications of the $A P O B$ mutation on cholesterol synthesis and turnover remain to be investigated.

\section{CONCLUSIONS}

Concentrations of circulating cholesterol and cholesterol in lipoprotein fractions were markedly lowered in Holstein cows heterozygous for the $A P O B$ mutation compared with noncarriers. The effect of the $A P O B$ mutation on the phenotypic expression of circulating cholesterol was persistent throughout lactation in heterozygous carriers. However, lactational and reproductive performance were not impaired compared with that of noncarriers. Parameters related to intermediary energy metabolism were not affected by the mutation, indicating that metabolic adaptations are successful and do not provoke a higher incidence of metabolic disorders. The low cholesterol concentrations associated with the $A P O B$ mutation are not the result of a primary deficiency of cholesterol, as the term "cholesterol deficiency" suggests, but rather are a consequence of a decreased ability to be incorporated into lipoproteins for transport in circulation. Our results indicate no need to eradicate $A P O B$ carriers from production. However, risk-matings of carriers should be avoided.

\section{REFERENCES}

Bauchart, D. 1993. Lipid absorption and transport in ruminants. J. Dairy Sci. 76:3864-3881. https://doi.org/10.3168/jds.S0022 -0302(93)77728-0.

Bobe, G., J. W. Young, and D. C. Beitz. 2004. Invited review: Pathology, etiology, prevention and treatment of fatty liver in dairy cows. J. Dairy Sci. 87:3105-3124. https://doi.org/10.3168/jds.S0022 -0302(04)73446-3.

Brunner, N., S. Groeger, J. Canelas Raposo, R. M. Bruckmaier, and J. J. Gross. 2019. Prevalence of subclinical ketosis and production diseases in dairy cows in Central and South America, Africa, Asia, Australia and New Zealand, and Eastern Europe. Transl. Anim. Sci. 3:84-92. https://doi.org/10.1093/tas/txy102.

Cebra, C. K., F. B. Garry, D. M. Getzy, and M. J. Fettman. 1997. Hepatic lipidosis in anorectic, lactating Holstein cattle: A retrospective study of serum biochemical abnormalities. J. Vet. Intern. Med. 11:231-237.

Cole, J. B., D. J. Null, and P. M. VanRaden. 2016. Phenotypic and genetic effects of recessive haplotypes on yield, longevity, and fertility. J. Dairy Sci. 99:7274-7288. https://doi.org/10.3168/jds.2015 -10777 .

Cole, J. B., P. M. VanRaden, D. J. Null, J. L. Hutchinson, T. A. Cooper, and S. M. Hubbard. 2018. Haplotype tests for recessive disorders that affect fertility and other traits. Animal Improvement Program AIP research report GENOMIC3 (09-13), Updated Dec. 1, 2018, Animal Genomics and Improvement Laboratory, Agricultural Research Service, USDA, Beltsville, MD. Accessed Mar. 22, 2019. https://aipl.arsusda.gov/reference/recessive_haplotypes ARR-G3.html.

Duff, J. P., S. Passant, M. Wessels, C. Charlier, G. Hateley, and R. M. Irvine. 2016. Cholesterol deficiency causing calf illthrift and diarrhoea. Vet. Rec. 178:424-425. https://doi.org/10.1136/vr.i2265.

Friedewald, W. T., R. I. Levy, and D. S. Fredrickson. 1972. Estimation of the concentration of low-density lipoprotein cholesterol in plasma, without use of the preparative ultracentrifuge. Clin. Chem. 18:499-502.

Gross, J. J., E. C. Kessler, C. Albrecht, and R. M. Bruckmaier. 2015. Response of the cholesterol metabolism to a negative energy bal- 
ance in dairy cows depends on the lactational stage. PLoS One 10:e0121956. https://doi.org/10.1371/journal.pone.0121956.

Gross, J. J., F. J. Schwarz, K. Eder, H. A. van Dorland, and R. M. Bruckmaier. 2013. Liver fat content and lipid metabolism in dairy cows during early lactation and during a mid-lactation feed restriction. J. Dairy Sci. 96:5008-5017. https://doi.org/10.3168/jds 2012-6245.

Gross, J. J., A. C. Schwinn, F. Schmitz-Hsu, F. Menzi, C. Drögemüller, C. Albrecht, and R. M. Bruckmaier. 2016. Rapid communication: Cholesterol deficiency-associated APOB mutation impacts lipid metabolism in Holstein calves and breeding bulls. J. Anim. Sci. 94:1761-1766. https://doi.org/10.2527/jas.2016-0439.

Gross, J. J., H. A. van Dorland, R. M. Bruckmaier, and F. J. Schwarz. 2011. Performance and metabolic profile of dairy cows during a lactational and deliberately induced negative energy balance with subsequent realimentation. J. Dairy Sci. 94:1820-1830. https://doi .org/10.3168/jds.2010-3707.

Grummer, R. R. 1993. Etiology of lipid-related metabolic disorders in periparturient dairy cows. J. Dairy Sci. 76:3882-3896. https://doi .org/10.3168/jds.S0022-0302(93)77729-2.

Häfliger, I. M., S. Hofstetter, T. Mock, M. H. Stettler, M. Meylan, K. Mehinagic, N. Stokar-Regenscheit, and C. Drögemüller. 2019. $A P O B$-associated cholesterol deficiency in Holstein cattle is not a simple recessive disease. Anim. Genet. 50:372-375. https://doi .org/10.1111/age.12801.

Hooper, A. J., J. R. Burnett, and G. F. Watts. 2015. Contemporary aspects of the biology and therapeutic regulation of the microsomal triglyceride transfer protein. Circ. Res. 116:193-205. https:/ /doi.org/10.1161/CIRCRESAHA.116.304637.

Kauppinen, K. 1984. ALAT, AP, ASAT, GGT, OCT activities and urea and total bilirubin concentrations in plasma of normal and ketotic dairy cows. Zentralbl. Veterinarmed. A 31:567-576.

Kessler, E. C., J. J. Gross, R. M. Bruckmaier, and C. Albrecht. 2014. Cholesterol metabolism, transport, and hepatic regulation in dairy cows during transition and early lactation. J. Dairy Sci. 97:54815490. https://doi.org/10.3168/jds.2014-7926.

Kipp, S., D. Segelke, S. Schierenbeck, F. Reinhardt, R. Reents, C. Wurmser, H. Pausch, R. Fries, G. Thaller, J. Tetens, J. Pott, D. Haas, B. B. Raddatz, M. Hewicker-Trautwein, I. Proios, M. Schmicke, and W. Grünberg. 2016. Identification of a haplotype associated with cholesterol deficiency and increased juvenile mortality in Holstein cattle. J. Dairy Sci. 99:8915-8931. https://doi .org/10.3168/jds.2016-11118.

Kulinski, A., S. Rustaeus, and J. E. Vance. 2002. Microsomal triacylglycerol transfer protein is required for lumenal accretion of triacylglycerol not associated with ApoB, as well as for ApoB lipidation. J. Biol. Chem. 277:31516-31525. https://doi.org/10.1074/ jbc.M202015200.

McArt, J. A. A., D. V. Nydam, and G. R. Oetzel. 2012. Epidemiology of subclinical ketosis in early lactation dairy cattle. J. Dairy Sci. 95:5056-5066. https://doi.org/10.3168/jds.2012-5443.
Menzi, F., N. Besuchet-Schmutz, M. Fragnière, S. Hofstetter, V. Jagannathan, T. Mock, A. Raemy, E. Studer, K. Mehinagic, N. Regenscheit, M. Meylan, F. Schmitz-Hsu, and C. Drögemüller. 2016. A transposable element insertion in APOB causes cholesterol deficiency in Holstein cattle. Anim. Genet. 47:253-257. https://doi .org/10.1111/age.12410.

Mock, T., K. Mehinagic, F. Menzi, E. Studer, A. Oevermann, M. H Stoffel, C. Drögemüller, M. Meylan, and N. Regenscheit. 2016. Clinicopathological phenotype of autosomal recessive cholesterol deficiency in Holstein cattle. J. Vet. Intern. Med. 30:1369-1375. https://doi.org/10.1111/jvim.13976.

Raboisson, D., M. Mounié, and E. Maigné. 2014. Diseases, reproductive performance, and changes in milk production associated with subclinical ketosis in dairy cows: A meta-analysis and review. J. Dairy Sci. 97:7547-7563. https://doi.org/10.3168/jds.2014-8237.

Saleem, S., C. Heuer, C. Sun, D. Kendall, J. Moreno, and R. Vishwanath. 2016. Technical note: The role of circulating low-density lipoprotein levels as a phenotypic marker for Holstein cholesterol deficiency in dairy cattle. J. Dairy Sci. 99:5545-5550. https://doi .org $/ 10.3168 /$ ids. 2015-10805.

Schlegel, G., R. Ringseis, J. Keller, F. J. Schwarz, and K. Eder. 2012 Changes in the expression of hepatic genes involved in cholesterol homeostasis in dairy cows in the transition period and at different stages of lactation. J. Dairy Sci. 95:3826-3836. https://doi.org/10 $.3168 /$ jds.2011-5221.

Schütz, E., C. Wehrhahn, M. Wanjek, R. Bortfeld, W. E. Wemheuer, J. Beck, and B. Brenig. 2016. The Holstein Friesian lethal haplotype 5 (HH5) results from a complete deletion of TBF1M and cholesterol deficiency (CDH) from an ERV-(LTR) insertion into the coding region of APOB. PLoS One 11:e0154602. https://doi .org/10.1371/journal.pone.0154602.

Steen, A. 2001. Field study of dairy cows with reduced appetite in early lactation: Clinical examinations, blood and rumen fluid analyses. Acta Vet. Scand. 42:219-228.

Stojević, Z., J. Piršljin, S. Milinković-Tur, M. Zdelar-Tuk, and B. B. Ljubić. 2005. Activities of AST, ALT and GGT in clinically healthy dairy cows during lactation and in the dry period. Vet. Arh. 75:67-73.

Suthar, V. S., J. Canelas-Raposo, A. Deniz, and W. Heuwieser. 2013 Prevalence of subclinical ketosis and relationships with postpartum diseases in European dairy cows. J. Dairy Sci. 96:2925-2938. https://doi.org/10.3168/jds.2012-6035.

Vicari, T., J. J. G. C. van den Borne, W. J. J. Gerrits, Y. Zbinden, and J. W. Blum. 2008. Postprandial blood hormone and metabolite concentrations influenced by feeding frequency and feeding level in veal calves. Domest. Anim. Endocrinol. 34:74-88. https://doi.org/ 10.1016/j.domaniend.2006.11.002.

Walsh, R. B., J. S. Walton, D. F. Kelton, S. J. LeBlanc, K. E. Leslie, and T. F. Duffield. 2007. The effect of subclinical ketosis in early lactation on reproductive performance of postpartum dairy cows. J. Dairy Sci. 90:2788-2796. https://doi.org/10.3168/jds.2006-560. 